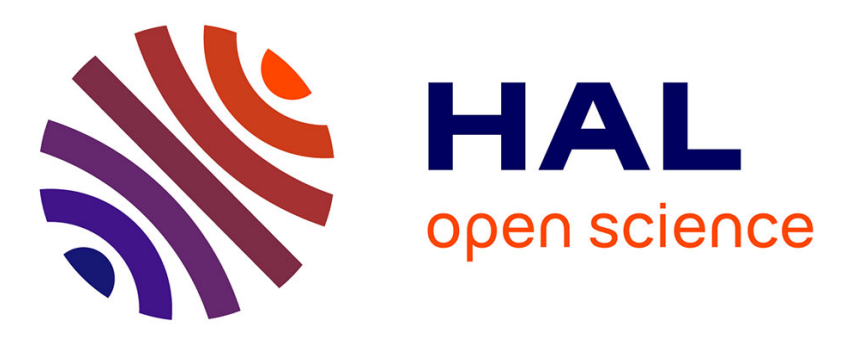

\title{
Compact and highly stable quantum dots through optimized aqueous phase transfer
}

Sudarsan Tamang, Grégory Beaune, Cathy Poillot, Michel de Waard, Isabelle Texier-Nogues, Peter Reiss

\section{- To cite this version:}

Sudarsan Tamang, Grégory Beaune, Cathy Poillot, Michel de Waard, Isabelle Texier-Nogues, et al.. Compact and highly stable quantum dots through optimized aqueous phase transfer. Colloidal quantum dots/Nanocrystals for biomedical applications VI, Jan 2011, San Francisco-CA, United States. pp.79091B-79091B-6. inserm-00647054

\section{HAL Id: inserm-00647054 https://www.hal.inserm.fr/inserm-00647054}

Submitted on 1 Dec 2011

HAL is a multi-disciplinary open access archive for the deposit and dissemination of scientific research documents, whether they are published or not. The documents may come from teaching and research institutions in France or abroad, or from public or private research centers.
L'archive ouverte pluridisciplinaire HAL, est destinée au dépôt et à la diffusion de documents scientifiques de niveau recherche, publiés ou non, émanant des établissements d'enseignement et de recherche français ou étrangers, des laboratoires publics ou privés. 


\title{
Compact and highly stable quantum dots through optimized aqueous phase transfer
}

\author{
Sudarsan Tamang ${ }^{\mathrm{a}}$, Grégory Beaune ${ }^{\mathrm{a}, \mathrm{b}}$, Cathy Poillot ${ }^{\mathrm{c}}$, Michel De Waard ${ }^{\mathrm{c}}$, \\ Isabelle Texier-Nogues ${ }^{\mathrm{b}}$, Peter Reiss ${ }^{* \mathrm{a}}$ \\ ${ }^{a}$ CEA-Grenoble, INAC-SPrAM (UMR 5819 CEA-CNRS-UJF) -LEMOH, 17 rue des Martyrs, 38054 \\ Grenoble cedex 9, France; \\ ${ }^{\mathrm{b}}$ CEA-Grenoble, LETI-DTBS, 17 rue des Martyrs, 38054 Grenoble cedex 9, France; \\ ${ }^{c}$ Grenoble Institute of Neuroscience, Inserm U 836, Université Joseph Fourier, Site santé de la \\ Tronche, BP 170, 38042 Grenoble cedex 9, France
}

\begin{abstract}
A large number of different approaches for the aqueous phase transfer of quantum dots have been proposed. Surface ligand exchange with small hydrophilic thiols, such as L-cysteine, yields the lowest hydrodynamic diameter. However, cysteine is prone to dimer formation, which limits colloidal stability. We demonstrate that precise $\mathrm{pH}$ control during aqueous phase transfer dramatically increases the colloidal stability of InP/ZnS quantum dots. Various bifunctional thiols have been applied. The formation of disulfides, strongly diminishing the fluorescence QY has been prevented through addition of appropriate reducing agents. Bright InP/ZnS quantum dots with a hydrodynamic diameter $<10 \mathrm{~nm}$ and longterm stability have been obtained. Finally we present in vitro studies of the quantum dots functionalized with the cellpenetrating peptide maurocalcine.
\end{abstract}

Keywords: Quantum dots, nanocrystals, phase transfer, cysteine, cell penetration peptides, maurocalcine.

\section{INTRODUCTION}

In recent years a large number of methods for the aqueous phase transfer of CdSe based quantum dots, synthesized in organic solvent, have been developed [1]. Among those, surface ligand exchange with small hydrophilic thiols has been shown to yield the lowest hydrodynamic diameter, on the order of 5-10 nm [2]. Compact quantum dots are required for specific imaging applications (e.g. sentinel lymph node detection, study of synaptic signaling) and for maximizing renal excretion in in vivo studies [3-5]. Thiol-containing amino acids such as L-cysteine are of particular interest as capping ligands for hydrosoluble quantum dots as they exhibit low non-specific binding to serum proteins due to their zwitterionic character. However, cysteine is prone to dimer formation, yielding cystine, which limits the colloidal stability of the quantum dots.

Here we demonstrate that the precise control of the $\mathrm{pH}$ value during aqueous phase transfer dramatically increases the colloidal stability of InP/ZnS quantum dots. While precipitation of the quantum dots in PBS buffer typically occurs within one day, DLS measurements show that no aggregation takes place even after several weeks in case of the correct choice of the $\mathrm{pH}$ during the transfer reaction. In addition to cysteine, various other bifunctional thiols have been tested. Depending on the phase transfer ligand, the $\mathrm{pH}$ has to be chosen in a range of 8-10 according to the $\mathrm{pK}_{\mathrm{a}}$ value of the thiol function. The thiolate ion exhibits a much stronger binding to the quantum dot surface than the thiol. At the same time, the formation of disulfides has been prevented during phase transfer through addition of appropriate reducing agents. Disulfides not only reduce the colloidal stability but also significantly diminish the fluorescence quantum yield (QY) of $\mathrm{InP} / \mathrm{ZnS}$ quantum dots. This effect is most pronounced (around $10 \%$ of QY retained) in the case of cysteine or dihydrolipoic acid used as phase transfer agents. To the contrary, in our procedure up to $90 \%$ of the initial QY is maintained. The resulting quantum dots emit in the range of $650-700 \mathrm{~nm}$ and exhibit a QY of $10 \%$ in PBS buffer at $\mathrm{pH}$ 7.4. Their hydrodynamic diameter lies below $10 \mathrm{~nm}$ and does not vary over several weeks. Finally we will present first in vitro studies of the hydrosoluble quantum dots after surface functionalization with the cell penetration peptide maurocalcine.

*peter.reiss@ @ea.fr; phone +33 43878 9719; fax +33 438785113. 


\section{RESULTS AND DISCUSSION}

\subsection{Aqueous phase transfer}

Aqueous phase transfer of InP/ZnS quantum dots (QDs) synthesized in 1-octadecene and capped with myristic acid/stearic acid is achieved by the vigorous stirring of a biphasic mixture of the initial particles in chloroform and of the transfer ligand in deionized water (Fig. 1a). The key feature for obtaining high colloidal stability is the precise control of the $\mathrm{pH}$ value of the aqueous phase containing the transfer ligand. On the one hand, the $\mathrm{pH}$ has to be high enough to deprotonate the thiol function of the transfer ligand. The thiolate function has been shown to have a much higher binding energy on QD surfaces than the thiol group [6]. On the other hand, elevated $\mathrm{pH}$ values promote the formation of disulfide bonds, which lead to weaker binding to the QD surface and to fluorescence quenching (see below). A number of bifunctional thiols has been investigated, namely DHLA (dihydrolipoic acid), Cys (L-cysteine), MPA (mercaptopropionic acid), Pen (D-penicillamine). Fig. 1c, showing the quantum dots in PBS 1X buffer at pH 7.4 under UV light, demonstrates that the fluorescence intensity of the QDs is strongly affected by the nature of the transfer ligand. However, both the UV-vis absorption and PL spectra remain essentially unchanged during the phase transfer as far as the peak position and line width are concerned (Fig. 1d).

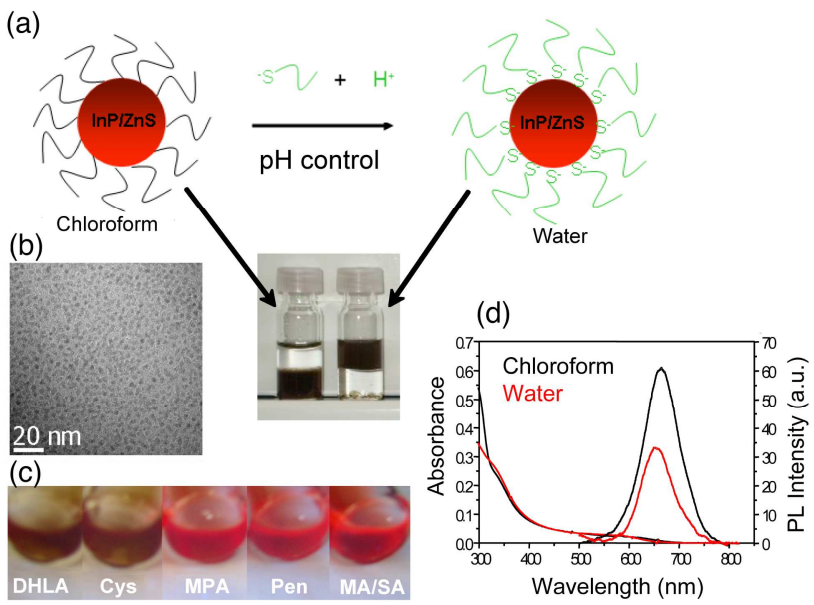

Figure 1. (a) Transfer of InP/ZnS quantum dots from the organic phase (chloroform) to the aqueous phase (DI water or buffer solution). (b) TEM image of the used quantum dots. (c) Photographs of samples transferred using different bifunctional thiols under UV light (DHLA: dihydrolipoic acid, Cys: L-cysteine, MPA: mercaptopropionic acid, Pen: Dpenicillamine) compared to the sample in chloroform (MA/SA: myristic acid/stearic acid). (d) UV-vis absorption and PL spectra of the InP/ZnS quantum dots before (chloroform) and after (water) phase transfer using L-cysteine.

In order to identify the appropriate $\mathrm{pH}$ value for the phase transfer, titration curves of the different ligands were established using tetramethylammonium hydroxide (TMAH) as the base. Table 1 lists the obtained $\mathrm{pK}_{\mathrm{a}}$ values of the thiol function of the different ligands studied (for DHLA: first thiol group). The $\mathrm{pH}$ value of the aqueous phase used in the transfer reaction was chosen to be slightly above $\mathrm{pK}_{\mathrm{a}}$ (thiol). Table 1 confirms the qualitative impression from Fig. 1c: the retained fluorescence quantum yield (QY) with respect to the initial value $(12 \%)$ varies strongly with the nature of the new surface ligand. While MPA and Pen conserve around one third of the QY, with Cys and DHLA only 4 and $10 \%$ are retained, respectively.

Table 1. Ligands used for the phase transfer, $\mathrm{pK}_{\mathrm{a}}$ values of the (first) thiol group, chosen $\mathrm{pH}$ value for the transfer reaction and retained PL QY as compared to the initial value (12\%).

\begin{tabular}{|lccc|}
\hline \multicolumn{4}{c|}{ AQUEOUS PHASE TRANSFER OF INP/ZNS QUANTUM DOTS } \\
Ligand & pK $_{\mathrm{a}}$ thiol group & Reaction pH & Retained PL QY \\
Dihydrolipoic acid (DHLA) & 10.7 & 11 & $10 \%$ \\
3-mercaptopropionic acid (MPA) & 10.8 & 11 & $34 \%$ \\
L-cysteine (Cys) & 8.35 & 9.3 & $4 \%$ \\
D-penicillamine & 7.9 & 9 & $30 \%$ \\
\hline
\end{tabular}




\subsection{Nuclear magnetic resonance and dynamic light scattering measurements}

After 24 hrs the samples exchanged with Cys exhibited a white precipitate, which cannot result from the aggregation of the (dark red) quantum dots. By means of ${ }^{1} \mathrm{H}-\mathrm{NMR}$ we identified this precipitate as being composed of cystine, the dimerisation product of cysteine (Fig. 2). Cystine is insoluble in water at neutral $\mathrm{pH}$. Therefore the precipitate was dissolved in a $\mathrm{D}_{2} \mathrm{O} / \mathrm{NaOH}$ mixture at $\mathrm{pH}$ 11. In L-cysteine (not shown), the methine proton and the methylene protons in $\alpha$-position of the thiol function have chemical shifts of 3.9 and $2.95 \mathrm{ppm}$, respectively. In the case of cystine precipitating from the quantum dots solution, the signal of the methine protons is shifted upfield to $3.46 \mathrm{ppm}$. The methylene protons split into two multipletts at 3.00 and $2.78 \mathrm{ppm}$, respectively, owing to the molecular chirality of the component (Fig. 2a). For comparison, the spectrum of pure L-cysteine (i.e. without quantum dots) kept at $\mathrm{pH} 9$ in $\mathrm{D}_{2} \mathrm{O}$ during $24 \mathrm{hrs}$ is also presented (Fig. 2b). The principal peaks of the obtained spectrum match those of the quantum dot solution. Both spectra are also in accordance with the data reported by Katritzky et al. and can therefore be unambiguously assigned to cystine [7]. It is well known that L-cysteine shows a strong tendency to generate insoluble cystine in the human body, which is one of the reasons for the formation of kidney stones. To the contrast, Dpenicillamine is much less prone to dimerization and can even be used as a treatment of cystinuria thanks to the solubility of cysteine-penicillamine [8]. For the various ligands studied, the degree of PL quenching can be correlated to their different tendency for disulfide formation. Disulfides such as cystine have been shown to efficiently quench the PL of CdTe quantum dots due to hole transfer [9]. We prevented disulfide formation by the addition of an appropriate reducing agent during the phase transfer, such as tris(2-carboyethyl)phosphine hydrochloride (TCEP). In this case, up to $90 \%$ of the initial PL quantum yield was retained, which is a significant improvement with respect to reported methods relying on ligand exchange for the water solubilization of quantum dots.

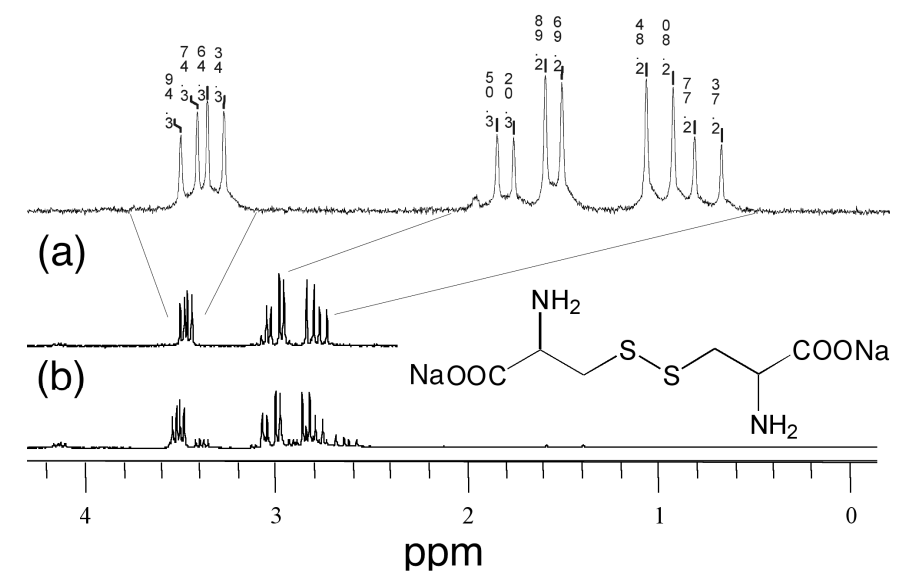

Figure 2. ${ }^{1} \mathrm{H}-\mathrm{NMR}$ spectra of (a) cystine recovered from NCs solution after $24 \mathrm{hrs}$ and (b) cystine formed when a solution of cysteine at $\mathrm{pH} 9$ is kept for $24 \mathrm{hrs}$ at room temperature. The spectra were recorded in a $\mathrm{D}_{2} \mathrm{O} / \mathrm{NaOH}$ mixture at $\mathrm{pH} 11$.

The hydrodynamic diameter of the transferred $\mathrm{InP} / \mathrm{ZnS}$ quantum dots was assessed by dynamic light scattering measurements. Importantly, the hydrodynamic diameter of Cys- or Pen-capped quantum dots is below $10 \mathrm{~nm}$ and no aggregation was detected for long periods of time up to several months (Fig. 3). We believe that strong ligand binding to the nanocrystals surface via the thiolate group is at the origin of the observed, significantly increased long-term stability as compared to exchange reactions carried out without $\mathrm{pH}$ control [10]. 


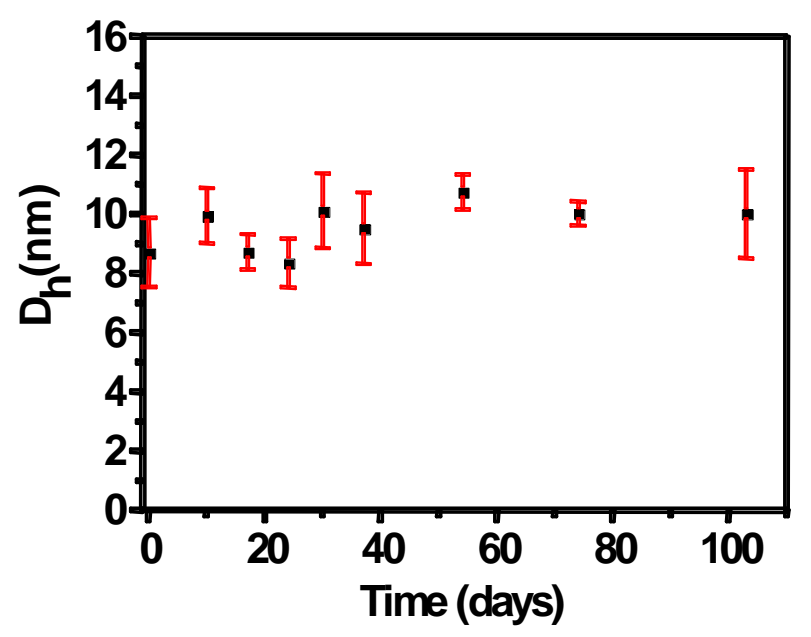

Figure 3. Hydrodynamic diameter as a function of time of cysteine-capped InP/ZnS NCs (concentration: $17 \mu \mathrm{M}$ ) in PBS $1 \mathrm{X}$ buffer. Black squares indicate the mean value of at least three measurements.

\subsection{Chiral properties and in vitro studies of Pen-capped quantum dots}

In the case of chiral D-penicillamine ligands, we carried out circular dichroism (CD) measurements. Fig. 4 illustrates that the Pen-functionalized quantum dots retain the chiral character of the capping molecules and exhibit a modified CD spectrum as compared to pure D-penicillamine. Gun'ko and coworkers synthesized chiral quantum dots in the presence of D- or L-penicillamine [11,12]. CD active luminescent nanocrystals are believed to have a high potential for the development of new chiral nanosensors. Our results indicate that chiral quantum dots can be obtained by post-synthetic ligand exchange, which gives an additional degree of freedom with respect to the use of optically active ligands during the synthesis.

(a)

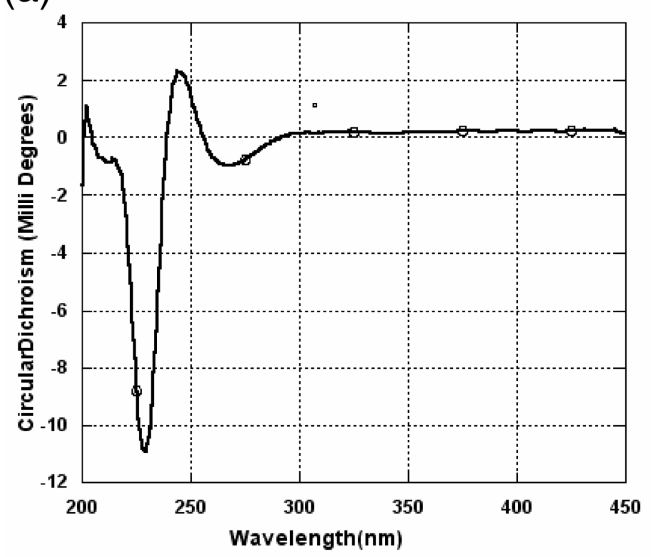

(b)

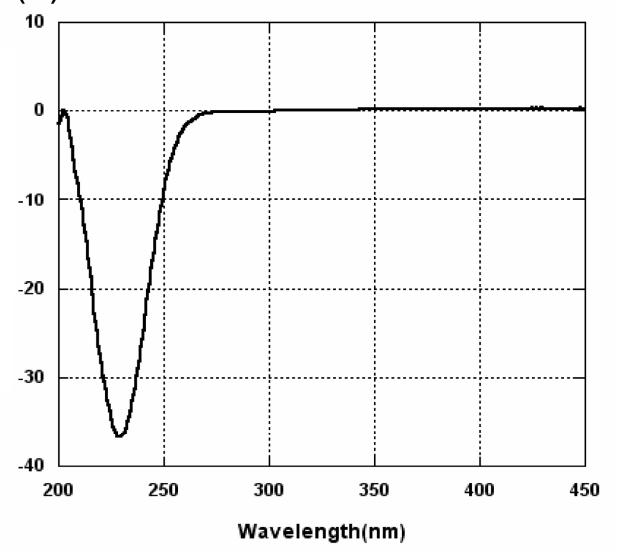

Figure 4. Circular dichroism spectra of (a) D-pencillamine capped InP/ZnS. QDs, (b) D-penicillamine.

Finally we demonstrate the possibility of using Pen-capped InP/ZnS quantum dots as a platform for further surface functionalization in view of biological applications. In this context, we used the cell penetrating peptide maurocalcine (MCa), which is able to bind to the quantum dot surface via the thiol function of one cysteine group [13]. MCa conjugation to the nanocrystals' surface was easily achieved by incubating the quantum dots in a solution containing an approximately 10-fold molar excess of MCa. After purification using centrifuge filters with a cut-off of $50 \mathrm{kDa}$, the MCa-functionalized quantum dots were used for incubation with Chinese hamster ovary (CHO) cells in culture (2 hrs). 
Fig. 5 demonstrates successful cell penetration of the MCa-modified quantum dots, whereas no penetration was observed with Pen being the only surface ligand. These results confirm that MCa is indeed bound to the nanocrystals' surface and that it retains its cell-penetration properties upon conjugation. Further experiments using tumor-targeting peptides in addition to $\mathrm{MCa}$ are currently underway in our laboratory, with the goal to demonstrate the versatility of the chosen approach and to provide multifunctional nanoprobes for biological applications.

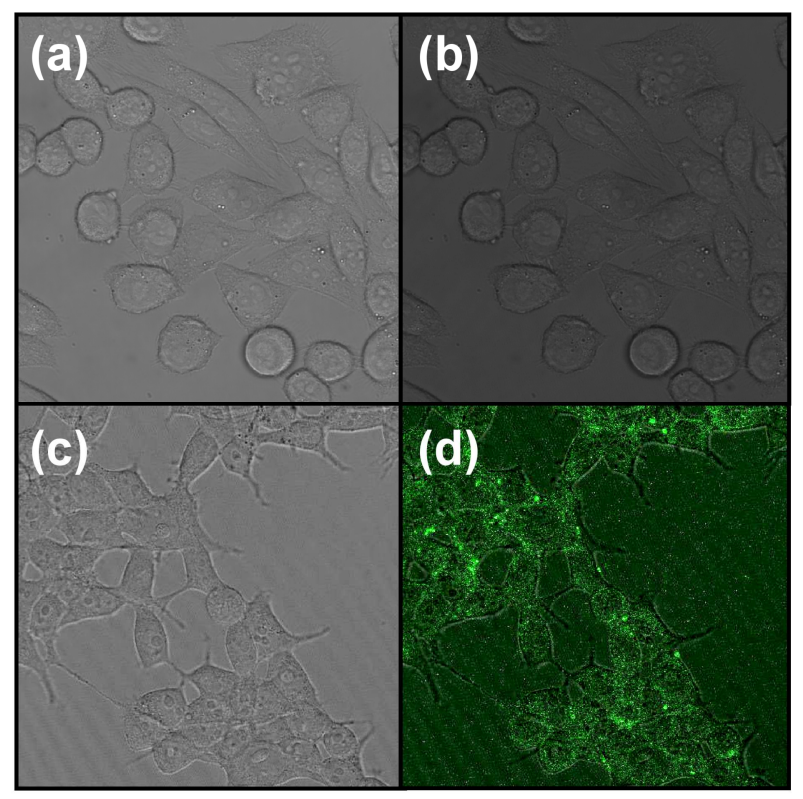

Figure 5. Confocal microscopy images of CHO cells showing successful cell penetration of MCa capped InP/ZnS QDs (incubation time: $2 \mathrm{hrs}$ ). Image size: 100x100 $\mu \mathrm{m}$. (a),(b) penicillamine-capped QDs; (c),(d) MCa-functionalized QDs; (a),(c) without excitation; (b),(d) excitation at $480 \mathrm{~nm}$; quantum dots in green (false colors).

\section{EXPERIMENTAL SECTION}

All reagents were purchased from Aldrich and used as received. The synthesis of InP/ZnS quantum dots follows the procedure reported in Ref [14].

Aqueous phase transfer: Sudarsan

Conjugation of MCa on the surface of InP/ZnS nanocrystals: Sudarsan

Measurement of the hydrodynamic diameter: Sudarsan

\section{ACKNOWLEDGEMENT}

We thank ?? for help with the circular dichroism measurements. We further acknowledge financial support from the French Research Agency (PNANO-07-NANO-044) and from CEA (Technologies pour la Santé “TIMOMA2”). 


\section{REFERENCES}

[1] Igor L. Medintz, H. Tetsuo Uyeda, Ellen R. Goldman and Hedi Mattoussi, "Quantum dot bioconjugates for imaging, labelling and sensing," Nature Materials 4, 435 - 446 (2005)

[2] Choi HS, Liu W, Liu F, Nasr K, Misra P, Bawendi MG, Frangioni JV. Design considerations for tumourtargeted nanoparticles. Nature Nanotechnology 2010, 5: 42-47

[3] Kim S, Lim YT, Soltesz EG, De Grand AM, Lee J, Nakayama A, Parker JA, Mihaljevic T, Laurence RG, Dor DM, Cohn LH, Bawendi MG, Fr. Near-infrared fluorescent type II quantum dots for sentinel lymph node mapping. Nature Biotechnology 2004, 22: 93-97.

[4] Maxime Dahan, Sabine Lévi, Camilla Luccardini, Philippe Rostaing, Béatrice Riveau, and Antoine Triller, "Diffusion Dynamics of Glycine Receptors Revealed by Single-Quantum Dot Tracking," Science 2003: 302 (5644), 442-445.

[5] Choi HS, Liu W, Misra P, Tanaka E, Zimmer JP, Kandapallil B, Bawendi MG, Frangioni JV. Renal Clearance of Nanoparticles. Nature Biotechnology 2007, 25: 1165 - 1170.

[6] Schapotschnikow P.; Hommersom B.; Vlugt T. J. H., Adsorption and Binding of Ligands to CdSe Nanocrystals, J. Phys. Chem. C. 2009, 113,12690-12698

[7] Alan R. Katritzky, Novruz G. Akhmedov and Olga V. Denisko, "1 H and ${ }^{13} \mathrm{C}$ NMR spectroscopic study of oxidation of D,L-cystine and 3,3-dithiobis(propionic acid) with hydrogen peroxide in aqueous solution," Magn. Reson. Chem. 2003; 41: 37-41.

[8] J. C. Crawhall, E. F. Scowen, C. J. Thompson, and R. W. E. Watts, "The Renal Clearance of Amino Acids in Cystinuria," Journal of Clinical Investigation Vol. 46, No. 7, 1967.

[9] Xia Y-S.; Zhu C-Q. "Interaction of CdTe nanocrystals with thiol-containing amino acids at different $\mathrm{pH}$ : a fluorimetric study," Microchimica Acta 2009, 164, 29-34.

[10]Liu, W.; Choi H.S.; Zimmer J.P.; Tanaka E.; Frangioni J.V.; Bawendi M., Compact Cysteine-Coated CdSe(ZnCdS) QDs for In Vivo Applications. J. Am. Chem. Soc. 2007, 129,14530-14531

[11] M. P. Moloney, Y. K. Gun'ko and J. M. Kelly, Chiral highly luminescent CdS quantum dots. Chem. Commun., 2007, 3900-3902.

[12] Joseph E. Govan, Edward Jan, Ana Querejeta, Nicholas A. Kotov and Yurii K. Gun'ko, Chiral luminescent CdS nano-tetrapods, Chem. Commun., 2010, 46, 6072-6074

[13]Eric Estève, ${ }^{1,2}$ Kamel Mabrouk, ${ }^{2}$ Alain Dupuis, ${ }^{1}$ Sophia Smida-Rezgui, ${ }^{1}$ Xavier Altafaj, ${ }^{1}$ Didier Grunwald, ${ }^{1}$ Jean-Claude Platel, ${ }^{1}$ Nicolas Andreotti, ${ }^{2}$ Isabelle Marty, ${ }^{1}$ Jean-Marc Sabatier, ${ }^{2}$ Michel Ronjat, ${ }^{1}$ and Michel De Waard $^{1^{*}}$, Transduction of the scorpion toxin maurocalcine into cells. Evidence that the toxin crosses the plasma membrane, J Biol Chem. 2005 April; 280(13): 12833-12839.

[14]Liang Li, Myriam, Protiere and Peter Reiss, "Economic synthesis of high quality InP nanocrystals using calcium phosphide as the phosphorus precursor," Chem. Mater.; 2008; 20, 2621 - 2623.

Model:

[15]Davis, A., R., Bush, C., Harvey, J. C. and Foley, M. F., "Fresnel lenses in rear projection displays," SID Int. Symp. Digest Tech. Papers 32(1), 934-937 (2001). 